Proceeding Paper

\title{
Interactions of Alkyl Gallates with SARS-CoV-2 Main Protease: A Molecular Docking Approach ${ }^{\dagger}$
}

\author{
Amalia Stefaniu *, Lucia Pintilie, Bujor Albu and Lucia Pirvu
}

Citation: Stefaniu, A.; Pintilie, L.; Albu, B.; Pirvu, L. Interactions of Alkyl Gallates with SARS-CoV-2 Main Protease: A Molecular Docking Approach. Proceedings 2021, 3 , 9. https://doi.org/10.3390/ ecsoc-24-08360

Academic Editors: Julio A. Seijas and M. Pilar Vázquez-Tato

Published: 14 November 2020

Publisher's Note: MDPI stays neutral with regard to jurisdictional claims in published maps and institutional affiliations.

Copyright: $(C) 2020$ by the authors. Licensee MDPI, Basel, Switzerland This article is an open access article distributed under the terms and conditions of the Creative Commons Attribution (CC BY) license (http://creativecommons.org/licenses/by/4.0/).

\begin{abstract}
National Institute for Chemical-Pharmaceutical Research and Development, 112 Vitan Av., 031299 Bucharest, Romania; lucia.pintilie@gmail.com (L.P.); abujor@gmail.com (B.A.);lucia.pirvu@yahoo.com (L.P.)

* Correspondence: astefaniu@gmail.com

+ Presented at the 24th International Electronic Conference on Synthetic Organic Chemistry, 15 November15 December 2020; Available online: https://ecsoc-24.sciforum.net/.
\end{abstract}

\begin{abstract}
Ten natural and semi-synthetic compounds (gallic acid and alkyl gallates) were investigated by in silico methods in order to evaluate their potential inhibitory activity against SAR-CoV2 using the X-ray structure of SARS-CoV-2 main protease bound to Boceprevir at $1.45 \AA$ (PDB ID: $6 \mathrm{WNP})$. The evaluation of drug-likeness in terms of Lipinski's Rule of Five and docking results in terms of docking score and interactions with the amino acids residues from the active binding site of the target protein were reported.
\end{abstract}

Keywords: gallic acid; alkyl gallates; SAR-CoV-2; molecular docking

\section{Introduction}

Severe acute respiratory syndrome coronavirus 2 has become a global health issue. Tremendous research efforts to elucidate the virus' action mechanisms and find specific treatments are in progress all over the world. Gallic acid possesses a promising structure for new drug design and development [1]. Antimicrobial activity was reported for alkyl gallates $[2,3]$. In our study, we intended to screen by molecular docking approach, a homologue series of alkyl gallates, starting form the lead compound-gallic acid, against the SARS-CoV-2 main protease.

\section{Methods for Molecular Docking Simulations}

The molecular docking study was realized using the CLC Drug, Discovery Work Bench. The protein fragment SARS-CoV-2 main protease bound to Boceprevir at $1.45 \AA$ (PDB ID: 6WNP) [4] was imported from the Protein Data Bank. Ligands' structures were constructed using the Spartan'16 program [5,6]; the lowest energy conformers were obtained and used forward for docking simulations. The viral protein contains three binding pockets: $48.13 \AA^{3}, 40.45 \AA^{3}, 36.62 \AA^{3}$. Water molecules were removed and amino acids residues form the binding site were protonated. The docking protocol was validated by redocking the co-crystallized ligand (Boceprevir). Intermolecular interactions occurring in Boceprevir and alkyl gallates-protein complexes were identified. The length of hydrogen bonding interactions was measured. The results were given in terms of docking score function and RMSD (root mean square deviation).

\section{Results and Discussions}

Figure 1 reveals the obtained docking scores for the co-crystallized ligand, gallic acid and alkyl gallates against the SARS-CoV-2 main protease (PDB ID: 6WNP). Boceprevir exhibits the greatest score of -63.95 , due to its numerous interactions with the amino acid residues from the protein's active binding site: eight hydrogen bonding interactions with nitrogen or oxygen atoms of amino acids residues, thus $\mathrm{N} \mathrm{sp}{ }^{2}$ CYS145 (2.900 $⿱$ A), N sp 2 


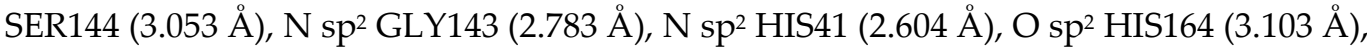

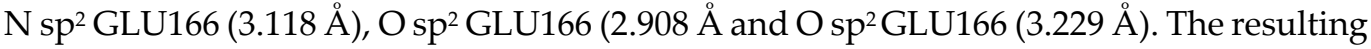
docking score of octyl gallate (-60.22, RMSD 1.12) is remarkable, close to Boceprevir.

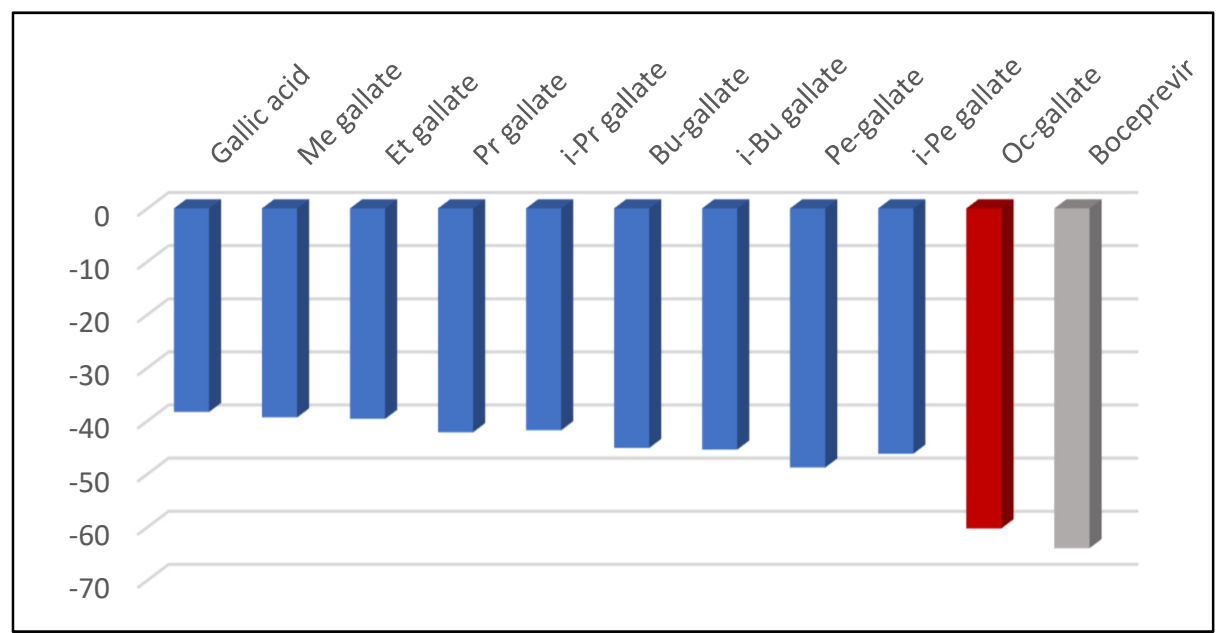

Figure 1. Docking scores for Boceprevir and the investigated alkyl gallates against the SARS-CoV2 main protease (PDB ID: 6WNP).

Figure 2 illustrates the hydrogen bond formed by octyl gallate (a) red-brown colored, and Boceprevir (b), in grey, respectively, with the amino acids from the active binding site, along with their surrounding interaction group-shown in Figure 2c,d, respectively.

In Table 1, we listed the amino acids group interactions, type and length of hydrogen bonding interactions formed by the co-crystallized Boceprevir and the alkyl gallate derivative with the greatest docking result, octyl gallate. The atomic numbering scheme of octyl gallate structure, determined as arbitrary by the Spartan software, is given in the Supplementary Material S1, available online. Its structure presents two flexible bonds, three hydrogen bond donors and five hydrogen bond acceptors. The molecular weight and the calculated water-octanol partition coefficient does not exceed the restrictions imposed by Lipinski's statement [7] regarding the oral bioavailability assessment. Thus, this molecule does not violate this rulesuggesting good permeation and absorption through the biological membranes. Clinical studies have revealed that gallic acid, catechins, flavones and quercetin glucosides have the best bioavailability in humans [8]. The 3,4,5-trihydroxybenzoic acid (gallic acid) is one of the most abundant phenolic acids in plants with various health benefits including anti-inflammatory and antioxidant activities [9]. The presence of phenyl ring, carboxyl moieties, and ester, hydroxyl and methoxy groups seems to be the basis of plants' phenolic antiviral efficacy [10,11]. On the other hand, semi-synthetic compounds, such as methylated or alkyl chain gallates, are good alternatives for designing and developing anti-viral agents. Their pharmacological activity is associated with the length of their alkyl side chain, which influences their membrane-binding abilities [2]. Generally, the membrane binding of the alkyl gallates increased with the increasing alkyl chain length and is correlated with their anti-viral activity. Increasing docking results were observed, with the increasing length of the n-alkyl side chain. 

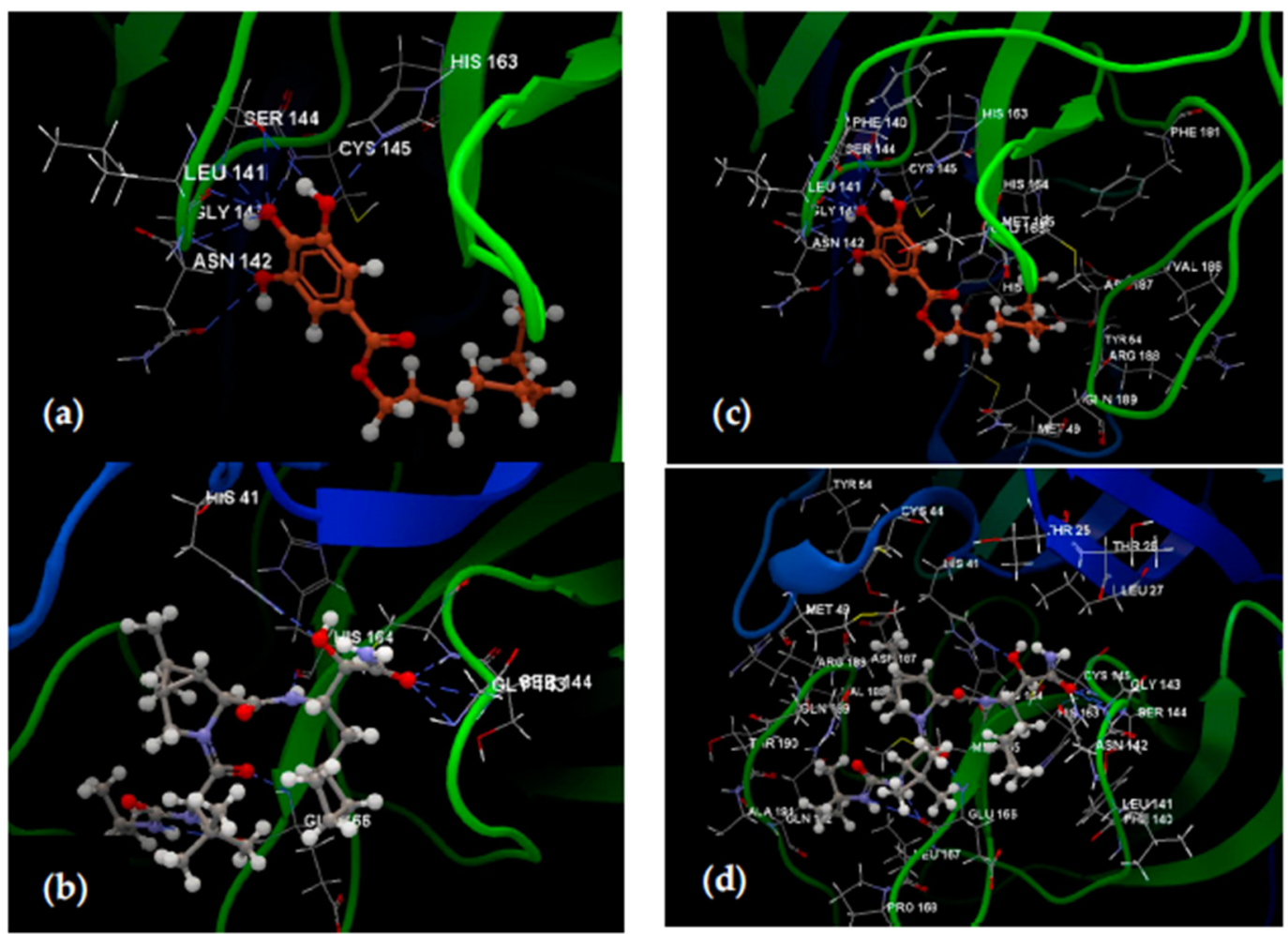

Figure 2. Hydrogen bonding interactions of octyl gallate (red-brown) (a) and Boceprevir (grey) (b) and their interactions with amino acids' residues from the active binding site of the $6 \mathrm{WNP}$ protein fragment $(\mathbf{c}, \mathbf{d})$, respectively.

Table 1. Depiction of intramolecular interactions formed by the natural ligand and octyl gallate with SARS-CoV-2 main protease $(6 \mathrm{WNP})$.

\begin{tabular}{|c|c|c|c|}
\hline Ligand & Group Interaction & Hydrogen Bond & Bond Length $(\AA ̊)$ \\
\hline \multirow{8}{*}{ Boceprevir } & \multirow{8}{*}{$\begin{array}{l}\text { TYR54, CYS44, HIS41, THR25, THR26, LEU27, MET49, } \\
\text { ARG188, ASP187, VAL186, GLN189, THR190 ALA191, } \\
\text { GLN192, PRO168, LEU167, GLU166, MET165, HIS165, } \\
\text { CYS145, GLY143, SER144, HIS163, LEU141, PHE140, ASN142 }\end{array}$} & $\mathrm{Osp} \mathrm{sp}^{2}(\mathrm{O} 01)-\mathrm{N} \mathrm{sp}^{2} \mathrm{CYS} 145$ & 2.900 \\
\hline & & $\mathrm{O} \mathrm{sp}{ }^{2}(\mathrm{O} 01)-\mathrm{N} \mathrm{sp}^{2}$ SER144 & 3.053 \\
\hline & & $\mathrm{O} \mathrm{sp}^{2}(\mathrm{O} 01)-\mathrm{N} \mathrm{sp}^{2}$ GLY143 & 2.783 \\
\hline & & $\mathrm{O} \mathrm{sp}^{3}(\mathrm{O} 04)-\mathrm{N} \mathrm{sp} \mathrm{HIS}^{2} 1$ & 2.604 \\
\hline & & $\mathrm{N} \mathrm{sp}^{2}(\mathrm{~N} 11)-\mathrm{O} \mathrm{sp}^{2} \mathrm{HIS164}$ & 3.103 \\
\hline & & O sp²(O35)-N sp² GLU166 & 3.118 \\
\hline & & $\mathrm{N} \mathrm{sp}^{2}$ (N27)-O sp² GLU166 & 2.908 \\
\hline & & $\mathrm{N} \mathrm{sp}^{2}(\mathrm{~N} 29)-\mathrm{O} \mathrm{sp}^{2} \mathrm{GLU166}$ & 3.229 \\
\hline \multirow{9}{*}{$\begin{array}{l}\text { Octyl } \\
\text { gallate }\end{array}$} & \multirow{9}{*}{$\begin{array}{c}\text { ASN142, GLY143, LEU141, SER144, PHE140, HYS163, CYS145, } \\
\text { HYS164, MET165, GLU166, HYS41, PHE181, VAL186, ASP187, } \\
\text { TYR54, ARG188, GLN189, MET49 }\end{array}$} & $\mathrm{O} \mathrm{sp}^{3}(\mathrm{O} 0)-\mathrm{O} \mathrm{sp}^{2} \mathrm{ASN} 142$ & 2.762 \\
\hline & & $\mathrm{Osp}{ }^{3}(\mathrm{O} 0)-\mathrm{N} \mathrm{sp}{ }^{2}$ GLY143 & 2.713 \\
\hline & & $\mathrm{Osp}{ }^{3}(\mathrm{O} 3)-\mathrm{N} \mathrm{sp}^{2}$ GLY143 & 2.980 \\
\hline & & $\mathrm{O} \mathrm{sp}^{3}(\mathrm{O} 3)-\mathrm{O} \mathrm{sp}^{2}$ LEU141 & 2.475 \\
\hline & & $\mathrm{O} \mathrm{sp}^{3}(\mathrm{O} 3)-\mathrm{N} \mathrm{sp}^{2} \mathrm{SER} 144$ & 2.696 \\
\hline & & $\mathrm{O} \mathrm{sp}^{3}(\mathrm{O} 3)-\mathrm{O} \mathrm{sp}^{3} \mathrm{SER} 144$ & 2.761 \\
\hline & & $\mathrm{O} \mathrm{sp}^{3}(\mathrm{O} 3)-\mathrm{N} \mathrm{sp}^{2} \mathrm{CYS} 145$ & 3.179 \\
\hline & & $\mathrm{O} \mathrm{sp}^{3}(\mathrm{O} 1)-\mathrm{O} \mathrm{sp}^{3} \mathrm{SER} 144$ & 3.390 \\
\hline & & $\mathrm{O} \mathrm{sp}^{3}(\mathrm{O} 1)-\mathrm{N} \mathrm{sp}^{2} \mathrm{HIS} 163$ & 2.849 \\
\hline
\end{tabular}

\section{Conclusions}

This in silico screening reveals the potential inhibitory action of alkyl gallates, mainly of octyl gallate against the SARS-CoV-2 main protease. The molecular docking simulations led to similar docking results for octyl gallate, compared to the natural ligand, Boceprevir. Further investigations are required in order to demonstrate and develop these preliminary conclusions. Similar docking results were the consequence of similar interactions. Amino acid residues CYS145 and SER144 interact by hydrogen bonding with both 
Boceprevir and with octyl gallate. Propyl gallate and pentyl gallate have reveal the same intra-molecular interactions with: $\mathrm{N} \mathrm{sp} 2$ GLU166, $\mathrm{N} \mathrm{sp}^{2}$ HIS163, O sp $\mathrm{sp}^{3}$ SER144, O sp ${ }^{3}$ SER144, O sp2 LEU141, N sp2 SER144, N sp² GLY143, N sp² CYS145, N sp2 GLY143, O sp 2 ASN142. Their obtained docking scores were -42.13 and -48.77 , respectively, lower than for octyl gallate, but greater than the results for gallic acid (-38.31). These findings prove that alkyl gallates are a good alternative for developing new therapeutical antiviral agents.

Funding: This research received no external funding.

Institutional Review Board Statement: Not applicable.

Informed Consent Statement: Not applicable.

\section{References}

1. Nayeem, N.; Smb, A. Gallic Acid: A Promising Lead Molecule for Drug Development. J. Appl. Pharm. 2016, 8, 1-4, doi:10.4172/1920-4159.1000213.

2. Takai, E.; Hirano, A.; Shiraki, K. Effects of alkyl chain length of gallate on self-association and membrane binding. J. Biochem. 2011, 150, 165-171, doi:10.1093/jb/mvr048.

3. Król, E.; Borges, A.D.S.; Da Silva, I.; Polaquini, C.R.; Regasini, L.O.; Ferreira, H.; Scheffers, D.-J. Antibacterial activity of alkyl gallates is a combination of direct targeting of FtsZ and permeabilization of bacterial membranes. Front. Microbiol. 2015, 6, 390, doi:10.3389/fmicb.2015.00390.

4. Anson, B.; Mesecar, A. 6WNP X-ray Structure of SARS-CoV-2 Main Protease Bound to Boceprevir at 1.45 A; Protein Data Bank: Piscataway, NJ, USA, 2020; Volume 4, p. 23, doi:10.2210/pdb6WNP/pdb.

5. Shao, Y.; Molnar, L.F.; Jung, Y.; Kussmann, J.; Ochsenfeld, C.; Brown, S.T.; Gilbert, A.T.B.; Slipchenko, L.V.; Levchenko, S.V.; O'Neill, D.P.; et al. Advances in methods and algorithms in a modern quantum chemistry program package. Phys. Chem. Chem. Phys. 2006, 8, 3172-3191, doi:10.1039/b517914a.

6. Hehre, W.J. A Guide to Molecular Mechanics and Quantum Chemical Calculations; Wavefunction, Inc.: Irvine, CA, USA, 2003.

7. Lipinski, C.A. Lead- and drug-like compounds: The rule-of-five revolution. Drug Discov. Today Technol. 2004, 1, 337-341, doi:10.1016/j.ddtec.2004.11.007.

8. Manach, C.; Scalbert, A.; Morand, C.; Rémésy, C.; Jiménez, L. Polyphenols: Food sources and bioavailability. Am. J. Clin. Nutr. 2004, 79, 727-747, doi:10.1093/ajcn/79.5.727.

9. Kahkeshani, N.; Farzaei, F.; Fotouhi, M.; Alavi, S.S.; Bahramsoltani, R.; Naseri, R.; Momtaz, S.; Abbasabadi, Z.; Rahimi, R.; Farzaei, M.H.; et al. Pharmacological effects of gallic acid in health and diseases: A mechanistic review. Iran. J. Basic Med. Sci. 2019, 22, 225-237, doi:10.22038/ijbms.2019.32806.7897.

10. Kamboj, A.; Saluja, A.K.; Kumar, M.; Atri, P. Antiviral activity of plant polyphenols. J. Pharm. Res. 2012, 5, $2402-2412$.

11. Park, E.-S.; Moon, W.-S.; Song, M.-J.; Kim, M.-N.; Chung, K.-H.; Yoon, J.-S. Antimicrobial activity of phenol and benzoic acid derivatives. Int. Biodeterior. Biodegrad. 2001, 47, 209-214, doi:10.1016/s0964-8305(01)00058-0. 